\title{
Integrative Management of Acute and Post- Operative Dental Pain
}

\author{
Leonard B. Goldstein*, Georgia Lymberopoulos and Ashley Marsh \\ Clinical Education Development, A.T. Still University, USA
}

Submission: February 10, 2017; Published: March 10, 2017

*Corresponding author: Leonard B. Goldstein, DDS, PhD, Assistant Vice President for Clinical Education Development, A.T. Still University, 5850 E. Still Circle, Mesa, AZ 85206, USA, Tel: 4802196195; Email: lgoldstein@atsu.edu

Keywords: Complementary and alternative medicines (CAM); Osteopathic therapy (OMM); Inter-professional education and collaboration (IPE/ IPC); Institute of Medicine (IOM); Trigeminal Neuralgia Tic Doloreux (TMDs,)

\section{Integrative Management of Acute and Post-Operative Dental Pain}

Pain management gone wrong is a national problem. There is actually an epidemic of pain medication abuse and addiction and dentistry is certainly part of that issue. However, if we all focus our attention on proper use of pain management, especially opioid medication, we can be part of the solution, while practicing safe integrative pain management and thus, reduce the risk, temptation and opportunity for opioid abuse.

The prevalence of pain is estimated to affect more than one hundred and sixteen million $(116,000,000)$ people in the United States, with an estimated cost of between 560-635 Billion dollars annually [1]! However, the increased use of opioid analgesics for pain management has also contributed to its increased misuse. It is estimated that more than 40,000 deaths are attributed annually to adverse drug reactions and overdoses [2]. Opioid drugs have contributed to drug mortality and morbidity with over 16,000 deaths associated with opioid prescribed pain management [3].

The use of complementary and alternative medicines (CAM) can be helpful in the integrative approach to dental pain management. "Integrative Medicine" is the conscientious and purposeful integration of CAM and conventional approaches to medicine (especially pain management), in a coordinated way. Medicine's leading accreditation, the Joint Commission, issued a "Clarification Standard" for pain treatment that significantly elevates numerous non-pharmacologic approaches [4]. The Joint Commission stated that the following were valuable:
A. Acupuncture therapy;
B. Manipulative therapy;
C. Osteopathic therapy (OMM); and,
D. Relaxation therapy.

The article also cautions clinicians to consider both the potential negative consequences of opioids as well as the potential positive value when making treatment decisions. This document puts a tremendous tool in the hands of practitioners and aims to promote integrative pain management [5].

Both integrative and interdisciplinary pain management is now the best methods to manage both acute and post-operative dental pain. While interdisciplinary (inter-professional education and collaboration -IPE/IPC) pain management involves multiple specialists utilizing a team-based approach; integrative care includes alternative and complimentary methods that augment traditional dental pain management [6].

While this approach should be the dominant approach in dental pain management, it is neither being taught nor utilized in the curriculum of many dental schools. Dentistry, when treating acute and/or post-operative pain, should be a team-oriented profession and we need to train our dental students and dentists as team players. Dental schools must introduce students to IPE and IPC. Students at this level have an intrinsic enthusiasm for learning. This enthusiasm should be embraced, but tempered with caution if the thinking is that dentistry should be exclusive. Dentist should embrace the contributions of other health professionals and function as a team, especially in the treatment of pain.

One of the best ways for the dentist or dental student to express leadership is to demonstrate appreciation for the value of other team member's contributions. This requires spending time learning what they do and allowing them to teach us about the areas of expertise that dentists do not have. Primary care physicians and dentists can play a prominent role in counseling patients regarding needed treatment options. In doing so, we are able to take a holistic, unbiased and evidence-based approach to treatment choices. 
Fortunately, a cultural shift has begun to take place in many academic institutions, with the recognition that Inter-professional education (IPE) and collaboration (IPC) approaches to integrative pain management are essential for delivering quality care. Since the Institute of Medicine (IOM) published reports on the importance of IPE/IPC and team-based care, IPE has gained acceptance as the consummate educational format in many academic centers $[7,8]$.

The pain management team may include physicians with fellowship training in pain management, mental health clinicians with experience in pain and addiction, pain management nurses, physical and occupational therapists, Physician Assistants, osteopathic physicians with expertise in manipulative therapy, licensed acupuncturists and pharmacists, to name a few [9].

Needless to say, it is rare that there will be a collaborative practice with all or most of these team members. However, it is incumbent upon the dental team to utilize an integrative approach; especially in the treatment of conditions such as TMDs, Trigeminal Neuralgia (Tic Doloreux) and acute post-operative/post-surgical pain. In a letter to the Department of Health and Human Services (September 6, 2016); ADA President Carol Gomez Summerhays, DDS and ADA Executive Director, Kathleen O'Loughlin, DMD, MPH, wrote:

"As the fifth most frequent prescribers of opioid analgesics, dentists are well-positioned to help keep these drugs from becoming a source of harm. We can be judicious about the dosage and number of pills we prescribe. When indicated, we can prescribe non-narcotic alternatives."

To expand upon that, we can and must utilize additional pain management strategies available by including integrative pain management treatment modalities. Integrative therapies, such as dietary supplementation, hypnosis, acupuncture and manual therapies can and should be utilized when appropriate, but only after developing a knowledge base and having qualified team members assist us in our treatment plan (e.g., licensed acupuncturist, nutritionist, osteopathic physician, etc.).

Resources for some information regarding CAM Therapies can be found at:

$$
\begin{aligned}
& \text { CAM------------------------------------nccih.nih.gov } \\
& \text { Dietary Supplements---------------ods.od.nih.gov } \\
& \text { Natural Medicines-------------------naturlmedicines.com }
\end{aligned}
$$

The use of integrative therapies continues to grow in the United States and many patients will continue to be interested in these approaches, as an addition to, or as an alternative to conventional approaches. In many cases, these therapies may only have modest effects on pain, but will certainly assist the practitioner who wants to limit the use of opioid medications, especially long-term, in the management of acute and post-operative dental pain.

There has been agreement among the analyses of the issue of pain management and the accompanying inadequacy of the prevalent medical/dental response to it [10-12]. We hope that this article will further the discussion of IPE/IPC-integrative strategies, leading ultimately to the development of a universally accepted, effective method of pain management.

\section{References}

1. Institute of Medicine (2011) Relieving Pain in America: A Blueprint for Transforming, Prevention, Care, Education, and Research. The National Academies Press, USA.

2. Centers for Disease Control and Prevention (2016) Opioids Drive Continued Increase in Drug Overdose Deaths. Centers for Disease Control and Prevention, USA.

3. James CM, Mack KA, Paulozzi U (2013) Pharmaceutical Overdose Deaths, United States 2010. JAMA 309(7): 657-659.

4. (2014) Revisions to Pain Management Standard Effective January 1, 2015. The Joint Commission website, USA.

5. Weeks K (2014) Chronicles of Health Creation: Joint Commission Issues New Pain Standards in Response to Integrative Medicine Team. Huffington Post Dec, USA.

6. Malone MA, Gloyer K (2013) Complimentary and Alternative Treatments in Sports Medicine. Primary Care 40(4): 945-968.

7. Courtivegy M, Bair A, Bakerjian D, Suzanne E, Jann MG, et al. (2013) Interprofessional Education: An Overview of Six Initiatives across the Schools of Health at a Single University. J Interprof Care 28(2): 155-156.

8. Kitts RL, Christodoulow J, Goldman S (2011) Promoting Interdisciplinary Collaboration: Trainees Addressing Siloed Medical Education. Academic Psychiatry 35(5): 317-321.

9. Pechak C, Gonzolez E, Summers C, Capshaw S (2013) Interprofessional Education: A Pilot Study of Rehabilitation sciences Students Participating in Interdisciplinary International Service Learning. J Allied Health 42(3): e61-e66.

10. Institute of Medicine (IOM, 2011)

11. The Mayday Fund (2009) A Call to revolutionize Chronic Pain Care in America: An Opportunity in Health Care Reform. The MayDay fund, USA.

12. Office of the Army surgeon General (2010) Pain Management Taskforce: Final Report. (Providing a Standardized DOD and VHA Vision and Approach to Pain Management to Optimize the Care of Warriors and Their Families) p. 1-76. 
Your next submission with Juniper Publishers will reach you the below assets

- Quality Editorial service

- Swift Peer Review

- Reprints availability

- E-prints Service

- Manuscript Podcast for convenient understanding

- Global attainment for your research

- Manuscript accessibility in different formats ( Pdf, E-pub, Full Text, Audio)

- Unceasing customer service

Track the below URL for one-step submission https://juniperpublishers.com/online-submission.php 